\title{
Blepharitis and Demodex spp. infection
}

\author{
Karolina Kot', Maciej Czepita², Danuta Kosik-Bogacka', Natalia tanocha-Arendarczyk', \\ Damian Czepita ${ }^{2}$ \\ ${ }^{1}$ Department of Biology and Medical Parasitology, Pomeranian Medical University, Szczecin, Poland \\ ${ }^{2}$ Department of Ophthalmology, Pomeranian Medical University, Szczecin, Poland
}

\begin{abstract}
According to the latest reports Demodex mites appear to play an important role in the pathogenesis of chronic blepharitis. Demodex mites are cosmopolitan and are present in many species of mammals. In this paper we describe two species that are found in humans: Demodex folliculorum and D. brevis. Infection occurs during direct contact with an affected person and also through contact with dust containing eggs of the parasite, through contact with bed linen, as well as cosmetics used together with an affected person. Treatment of chronic blepharitis caused by $D$. folliculorum and $D$. brevis is difficult and time consuming. Some improvement can be achieved after topical application of yellow mercury ointment, sulphuric ointment, camphor oil, crotamiton, cholinesterase inhibitors, sulfacetamide, steroids, antibiotics and antifungal drugs. Good results have been achieved with oral ivermectin and permethrin cream. However, the best results were observed after treatment with metronidazole.
\end{abstract}

KEY WORDS: pathogenesis, infection, ocular demodicosis, treatment

Ophthalmol J 2017; Vol. 2, No. 1, 22-27

\section{INTRODUCTION}

Blepharitis can be caused by bacterial or fungal infection, allergic reaction, metabolic disease, uncorrected refractive errors, and Demodex spp. Anterior blepharitis is usually caused by staphylococcal infection, while posterior blepharitis is usually related to meibomian gland dysfunction or seborrheic blepharoconjunctivitis. Recent reports have highlighted the importance of Demodex mites in the pathogenesis of chronic blepharitis, especially in cases with weak reaction to treatment. Recurrent hordeola and chalazia can be a result of Demodex spp. infection [1].

Demodex mites are cosmopolitan and are therefore found in different species of mammals. At the time of writing, two species have been found in humans: Demodex brevis (Akbulatova, 1963) and D. folliculorum (Simon, 1842). Recently these two species have been classified as parasites after previously being described as commensals [2]. However, the pathogenicity of these two species of mites is con- troversial because they can also be found in healthy individuals [3]. Based on the results of current studies, it is estimated that Demodex mites are present in $10 \%$ of healthy people and can be found in $12 \%$ of their hair follicles [4]. It is postulated that D. folliculorum becomes pathogenic when it reproduces intensively, causing increasing ocular symptoms [5].

\section{BIOLOGICAL PROPERTIES}

Demodex mites have a vermiform shape and are covered by a thin cuticle (Fig. 1). Demodex folliculorum are larger $(0.3-0.4 \mathrm{~mm})$ and are more elongated. They live in larger groups in the orifices of hair follicles. Demodex brevis is smaller (0.2$-0.3 \mathrm{~mm}$ ) and has a fusiform shape and short legs. It can be found in single sebaceous glands throughout the facial skin and also in the meibomian glands of the eyelids [6]. The body of Demodex mites can be divided into the gnathosoma with the mouthpart, the podosome, and the opisthosoma. In both 

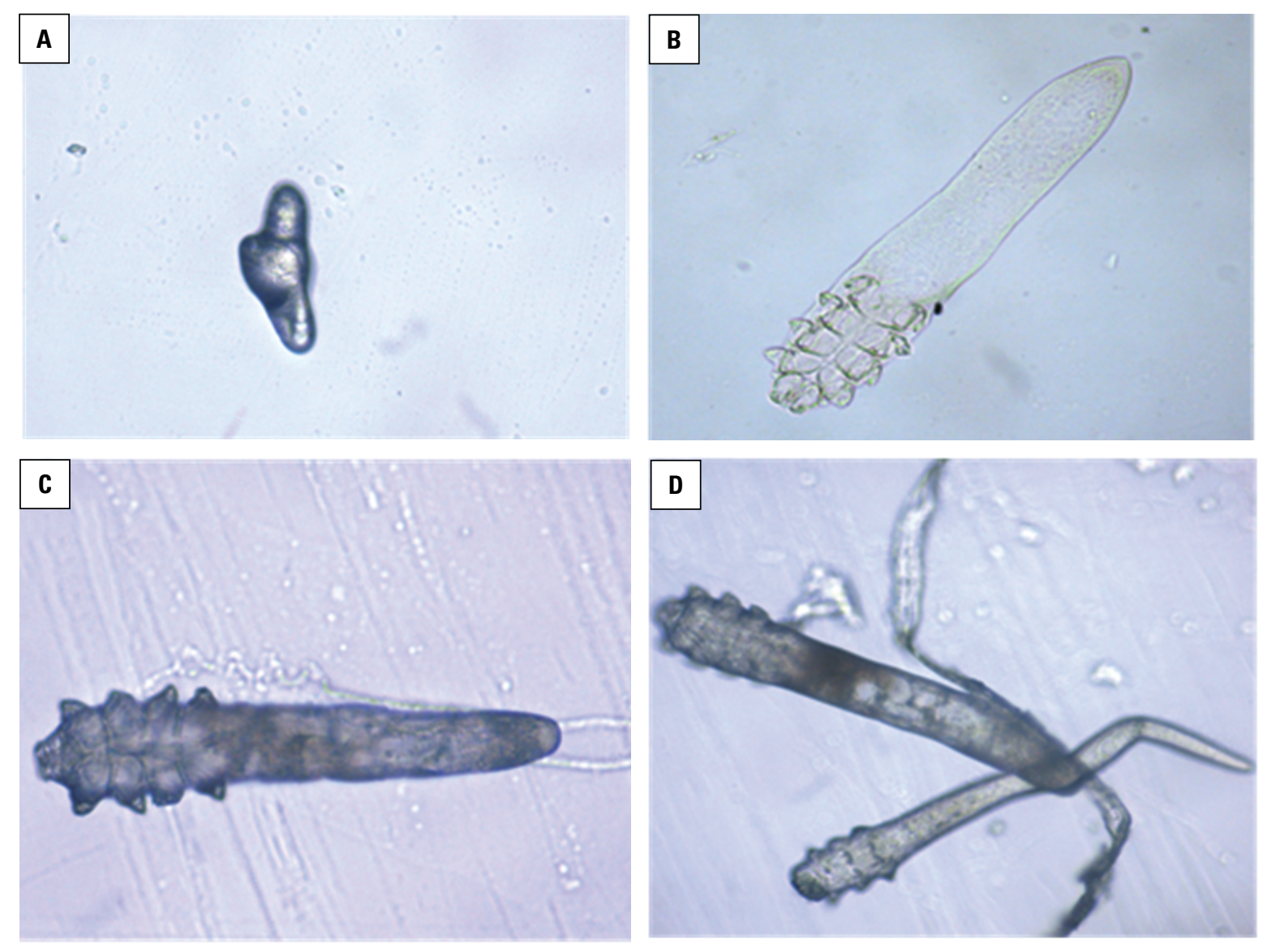

FIGURE 1. Developmental stages of Demodex folliculorum: A — egg; B-D — adults (magnification 100×)

species the podosome has four pairs of legs and three pairs in larvae. The gnathosoma of $D$. folliculorum contains sharp and more dagger-like mandibles than in $D$. brevis, which serve to take up food, and palps that are necessary to hold food. The mandibles serve to cut the epithelium of the hosts skin. The parasites excrete enzymes that can initially digest food, after which the mites suck it in. This form of feeding causes the destruction of the epithelium and the penetration of the parasite into the deeper layers of the skin. The main food source in all stages of development are the components of serum. As a result, the parasites thrive in areas that are especially rich in sebaceous glands [7-8]. The life cycle of $D$. folliculorum lasts between 14 and 18 days. The development is simple and it occurs in only one host. The female lays eggs, from which larvae initially without legs hatch. The larvae then develop three pairs of unsegmented legs. After the first moulting, the larvae transform into an eight-legged nymph, and after another two moultings into an adult form, either female or male [9].

Demodex spp. is sensitive to changes in temperature and $\mathrm{pH}$. The optimal temperature for the de- velopment of Demodex spp. ranges from 16 to $20^{\circ} \mathrm{C}$. The parasites stop feeding at temperatures below $0^{\circ} \mathrm{C}$ or above $37^{\circ} \mathrm{C}$. At temperatures above $54-58^{\circ} \mathrm{C}$ they die. Demodex mites prefer an acidic environment and are sensitive to UV radiation [10-11].

\section{EPIDEMIOLOGY}

Demodex folliculorum and D. brevis most often occur in elderly patients. Cheng et al. [12] found a prevalence rate of $84 \%$ in a population aged 60 years and almost $100 \%$ in a population over 70 years old. Garbacewicz et al. [13] noted a low prevalence in young people $(5 \%)$, which can probably be attributed to excretion of smaller amounts of sebum by the sebaceous glands of Zeiss and the Meibomian tarsal glands in children and teenagers [11].

Infection occurs through direct contact with an affected person and most likely through contact with dust containing eggs of the parasite, through contact with bed linen, or by sharing the same cosmetics with an affected person [14-15]. Moreover, 
it has been discovered that eggs of Demodex spp. can be found in microscope eyepieces. The results of studies carried out by Garbacewicz et al. [13] showed that $30 \%$ of people using a microscope were infected with Demodex spp.

The factors having an influence on Demodex spp. infection are profession, type of skin, dermatological illnesses, living standards, housing and work place standards, as well as personal hygiene habits [8]. Wesołowska et al. [16] found that Demodex spp. occurs in $40 \%$ of people of a medical profession such as doctors, nurses, and physiotherapists, and in $33.7 \%$ of medical students and $23.5 \%$ of drug abusers. Ocular demodicosis can be a result of the presence of mites on the facial skin [17-18]. Demodex spp. infection has been observed in $47 \%$ of people with oily skin, in $26.6 \%$ of people with dry skin, and in $33.9 \%$ of people with a mixed complexion. People with dermatological illnesses such as rosacea and skin acne are more susceptible to Demodex spp. infection (62\%) than healthy people (27.6\%). A higher infection rate has been also observed in patients living in areas of humid climate $(67.9 \%)$ than in people living in areas of dry climate (24.5\%) [19]. Wesołowska et al. [16] described a higher prevalence of Demodex spp. infection among people living in older housing $(43.5 \%)$ than among people living in newer housing $(39.4 \%)$. However, the difference was not statistically significant.

Some researchers have described the prevalence of Demodex spp. infection to be related to the sex of the examined patients. Raszeja-Kotelba et al. [20] and Forton et al. [21] have given a higher intensity of infection in women than in men, which was attributed to the use of creams and powders as well as being influenced by sex hormones. However, Horváth et al. [22] observed that the infection rate was higher in men than in women. Yamashita et al. [23] and Kuźna-Grygiel et al. [14] as well as Wesołowska et al. [16] did not find a relationship between sex and the prevalence of Demodex spp. infection. Dokuyucu et al. [24] examined the correlation of D. folliculorum infection and the body mass index (BMI). The results indicated that increased BMI influenced the prevalence of Demodex spp. infection. $26.3 \%$ of overweight or obese patients (BMI > 35) had D. folliculorum. A higher prevalence was also found in underweight patients (13.3\%). However, Gökçe et al. [25] did not find any relationship between the prevalence of $D$. folliculorum and BMI.

It has also been observed that Demodex spp. occurs more often in patients with lower immunity $[26,27]$.
Demodex spp. infection has been noted in patients with HIV, leukaemia, or cancer [28, 29]. Demodexspp. has been diagnosed in patients with diabetes, renal failure, and in patients undergoing haemodialysis $[3,25,28,30]$.

There are publications proving a relationship between Demodex spp. infection and blepharitis. Tian and Chao-Pin [31] examined 507 patients with blepharitis and noted that $50.7 \%$ of patients have Demodex spp. The authors also observed Demodex spp. in 58 patients $(11.7 \%)$ with other eye diseases. Türk et al. [32] observed D. folliculorum in $29.7 \%$ of patients with blepharitis, in $9.1 \%$ of patients with blepharoconjunctivitis, and in $4.2 \%$ of patients in a control group. Bhandari and Reddy [5] discovered the mites in $78.7 \%$ of people with chronic blepharitis. However, Kemal et al. [33] did not observe any statistically significant difference of the prevalence of Demodex spp. in patients with and without blepharitis. Wesołowska et al. [16] similarly did not observe any higher prevalence of demodicosis in people wearing eyeglasses or contact lenses.

\section{PATHOGENESIS}

Demodex mites feed on the cells lining hair follicles. Metabolites and undigested leftovers can accumulate at the base of eyelashes and create cylindrical dandruff, which is pathognomonic for ocular demodicosis [12]. Demodex spp. mechanically block sebaceous glands, irritate the eyelids, and induce hypertrophy of the epithelium and hyperkeratinisation. Demodex spp. may induce in the host a granulomatous inflammation and immunologic response [34-35]. Köksal et al. [36] have observed a granuloma within a Meibomian gland harbouring Demodex spp. and surrounded by epithelial cells, stromal cells, fibroblasts, lymphocytes, and plasmatic cells. In studies carried out by Liang et al. [37] demodicosis was found along with chalazia $69.2 \%$ more often than in the control group (20.3\%). Additionally, patients with demodicosis had a tendency to relapse (33.3\%), especially those infected with $D$. brevis, which is more often found than D. folliculorum in patients with chalazia.

Yam et al. [38] discovered Demodex mites in $72.9 \%$ of patients with recurrent chalazia. They concluded that recurrent chalazia is associated with ocular demodicosis.

Past studies have shown that in the aqueous humour of patients infected with Demodex spp. there is more interleukin 17 (IL-17), which causes 
inflammation and blockage of the glands. In addition, it can cause damage to the eye surface [39-40]. Akilov and Mumcuoglu [41] have shown that in people with demodicosis, the level of CD95+ is elevated, while CD3+, CD4+, CD8+, CD16+, and the $\mathrm{CD} 3+/ \mathrm{CD} 20+$ ratio is lower. No difference in the concentrations of $\operatorname{IgA}$, IgM, and $\operatorname{IgG}$ has been found. Kim et al. [39] examined the clinical and immunological response to Demodex spp. infection. A significant decrease in IL- $1 \beta$ and IL-17 was observed in patients receiving treatment. The level of IL-5, IL-7, IL-12, IL-13, G-CSF, and MIP- $1 \beta$ also decreased; however, the difference was not statistically significant. Demodex mites can avoid or suppress the immunological response of the host by inhibiting all three pathways of the complement system (classical, lectin and alternative) through scabies mite-inactivated serine protease paralogues and serine protease inhibitors [29].

\section{SYMPTOMS}

The clinical symptoms of ocular demodicosis are uncharacteristic and patients are frequently asymptomatic. Gao et al. [42] noted a correlation between the number of Demodex mites and the intensity of symptoms. Patients with blepharitis and diagnosed presence of Demodex mites have complained of symptoms such as: itchiness, a burning sensation, a feeling of heavy eyelids, excessive lacrimation, and the presence of mucous discharge [5]. Other symptoms of ocular demodicosis may include eyelid and conjunctival hyperaemia, madarosis, loss of eyebrows, photophobia, and excessive sensitivity to smoke and dust [11]. Gao et al. [42] noted Meibomian gland dysfunction in $63.6 \%$ and loss of eyelashes in $45.5 \%$ of people with diagnosed eyelid demodicosis. Kheirkhah et al. [43] observed meibomian gland dysfunction in $83.3 \%$, rosacea in $66.7 \%$, and decreased vision in $50 \%$ of patients with blepharitis caused by Demodex mites. Inceboz et al. [44] observed itchiness (61.7\%) and hyperaemia $(59.1 \%)$ in patients with $D$. folliculorum.

Untreated ocular demodicosis may lead to serious complications. Inflammation caused by a large number of parasites and serious symptoms of blepharitis may affect the cornea, conjunctiva, and cause neovascularisation, conjunctival hyperaemia, and conjunctiva of nipple follicles [8]. Patients treated using antibiotics or antiviral drugs may note a short improvement and decrease in symptoms. However, a delay in providing appropriate treatment may ulti- mately lead to corneal ulceration, corneal clouding, or the formation of white spots, which have a significant influence on visual acuity [8].

\section{DEMODEX SPP. AS A VECTOR}

It has been established that Demodex mites take part in the transmission of pathogens, which may play a prominent role in the pathogenesis of demodicosis [45]. Symptomatic demodicosis often coexists with bacterial infections, which can be confirmed by the decreasing number of Demodex mites after the treatment of patients with acne using tetracyclines [46]. Spickett [47] noted that D. folliculorum may be a vector organism for Mycobacterium leprae bacilli. Lacey et al. [48] isolated Bacillus oleronius from within the $D$. folliculorum of a patient of acne rosacea and specific antigens from the serum of examined patients. Similar results were reported by Szkaradkiewicz et al. [49]. They described both Demodex spp. and B. oleronius in patients with acute blepharitis. Clifford et al. [50] noted the coexistence of Staphylococcus aureus and D. folliculorum in patients with diabetes; however, such a situation was not described by Lee et al. [51]. Demodex spp. can take part in the transmission of fungi [52]. Hallur et al. [53] described a coinfection of $D$. folliculorum and Apophysomyces elegant in patients with decreased resistance.

\section{DIAGNOSIS}

In the diagnosis of ocular demodicosis, eyelashes are examined - a few are taken aseptically from both eyelids of both eyes. The material is examined under a light microscope at $100 \times$ magnification. It can be also examined in saline at $25 \times$ magnification. If cylindrical dandruff is present, $20 \mu \mathrm{L}$ of $100 \%$ alcohol or a $0.25 \%$ solution of fluorescein drops should be pipetted into the edge of the coverslip to enable the migration of the parasite. The time of examination extends to 20 minutes [17]. In the case of recurrent chalazia, the lesions can be taken for histopathological examination to determine the presence of Demodex mites [8].

\section{TREATMENT}

Treatment of chronic blepharitis caused by $D$. folliculorum and D. brevis is difficult and time consuming. Some improvement can be achieved after topical application of yellow mercury ointment, sulphuric ointment, camphor oil, crotamiton, cho- 
linesterase inhibitors, sulfacetamide, steroids, antibiotics, and antifungal drugs. Good results have been achieved with simultaneous oral ivermectin and permethrin cream [54-55]. Filho et al. [56] examined the effectiveness of oral ivermectin in patients with blepharitis with proven Demodex spp. infestation. Complete resolution was achieved 90 days after initiation of treatment independently of the intensity of the infection. Brown et al. [57] noted the case of a 12-year-old girl with serious ocular demodicosis and rosacea, who improved a month after receiving single-dose 12-mg therapy with ivermectin.

However, we obtained the best results after treatment with metronidazole. Therefore, we encourage the use of the following ointments:

- Metronidazoli - 0.5;

- Glycerini - 2.0;

- Vaselini albi ad - 20.0;

- M. f. unq. ophthalmicum;

- $\mathrm{S}$ - twice daily on eyelid margins;

and:

- Metronidazoli - 3.0;

- Hascobaza - 100.0;

- M.f. unq.;

- S - twice daily on face.

The treatment of ocular demodicosis takes between two and three months. Subsequently we check whether the parasite is still present. If $D e-$ modex spp. can still be found, then the treatment is continued for another 2-3 months [58].

A prepared formula of Spanish sage oil and lyophilised aloe is available on the market. Special handkerchiefs and solutions can be used in maintaining eyelid hygiene. The symptoms of ocular demodicosis can be alleviated by sunbathing, washing the skin of the face with a mixture of warm water and hexachlorobenzene.

The prophylaxis of Demodex spp. infection consists of rigorous eyelid care, improvement of personal hygiene, and not sharing towels and cosmetics with people infected with Demodex spp.

However, the role of Demodex spp. as a commensal should not be overlooked. Treatment should not be aimed at total eradication of the mite but rather restoration of the ocular ecology to a balanced state [59].

\section{REFERENCES}

1. Rodolfo $\mathrm{L}$, Rodriguez $\mathrm{OD}$, Blepharitis disease and its management. American Optometric Association, Paraoptometric Section. http:// www.aoa.org/documents/optometricstaff/blepharitis_disease_ and its management. pdf.

2. Rather $\overline{P A}$, Hassan I. Human demodex mite: the versatile mite of dermatological importance. Indian J Dermatol. 2014; 59(1): 60-66, doi: 10.4103/0019-5154.123498, indexed in Pubmed: 24470662.
3. Yagdiran Düzgün 0, Aytekin S. Comparison of Demodex folliculorum density in haemodialysis patients with a control group. J Eur Acad Dermatol Venereol. 2007; 21(4): 480-483, doi: 10.1111/j.14683083.2007.01926.x, indexed in Pubmed: 17373974.

4. Elston DM. Demodex mites: facts and controversies. Clin Dermatol. 2010; 28(5): 502-504, doi: 10.1016/j.clindermatol.2010.03.006, indexed in Pubmed: 20797509.

5. Bhandari V, Reddy JK. Blepharitis: always remember demodex. Middle East Afr J Ophthalmol. 2014; 21(4): 317-320, doi: 10.4103/09749233.142268, indexed in Pubmed: 25371637.

6. Gunnarsdottir S, Kristmundsson A, Freeman MA, et al. [Demodex folliculorum a hidden cause of blepharitis]. Laeknabladid. 2016; 102(5): 231-235, doi: 10.17992/lbl.2016.05.81, indexed in Pubmed: 27197131.

7. Izdebska JN. Roztocze skórne człowieka i zwierząt domowych. In: Majkowska-Wojciechowska B. ed. Alergologia w praktyce. Alergia na roztocze. Mediton, Łódź 2005: 95-105.

8. Zhang $X Y$, Sun $X G$. Progress of study on the demodex blepharitis. Zhonghua Yan Ke Za Zhi. 2016; 52(4): 315-320, indexed in Pubmed: 27094071.

9. Buczek A. Choroby pasożytnicze, epidemiologia, diagnostyka, objawy. Koliber, Lublin 2005.

10. Zhao Y, Guo N, Zeng X, et al. Morphology and Demodex mites survival temperature range of observation and research. Entomological $\mathrm{J}$. 2005; 48: 754-758.

11. Marcinowska Z, Kosik-Bogacka D, Lanocha-Arendarczyk N, et al. Demodex folliculorum and demodex brevis. Pomeranian J Life Sci. 2015; 61(1): 108-114, indexed in Pubmed: 27116866.

12. Cheng AMS, Sheha H, Tseng SCG. Recent advances on ocular Demodex infestation. Curr Opin Ophthalmol. 2015; 26(4): 295-300, doi: 10.1097/ICU.0000000000000168, indexed in Pubmed: 26058028.

13. Garbacewicz A, Udziela M, Grytner-Ziecina B, et al. Demodex infections in general Polish population, in patients suffering from blepharitis, and among people who work with microscopes. Klin Oczna. 2010; 112(10-12): 307-310, indexed in Pubmed: 21469525.

14. Kuźna-Grygiel W, Kosik-Bogacka D, Czepita D, et al. Objawowe i bezobjawowe inwazje Demodex spp. powiek u osób w różnych grupach wiekowych. Wiad Parazytol. 2004; 50: 55-61.

15. Buczek A. Choroby pasożytnicze. Koliber, Lublin 2010.

16. Wesolowska M, Knysz B, Reich A, et al. Prevalence of Demodex spp. in eyelash follicles in different populations. Arch Med Sci. 2014; 10(2): 319-324, doi: 10.5114/aoms.2014.42585, indexed in Pubmed: 24904668.

17. Liu J, Sheha H, Tseng SCG. Pathogenic role of Demodex mites in blepharitis. Curr Opin Allergy Clin Immunol. 2010; 10(5): 505-510, doi: 10.1097/ACl.0b013e32833df9f4, indexed in Pubmed: 20689407.

18. Arriaga C, Domingues M, Castela G, et al. Pediatric ocular rosacea, a misdiagnosed disease with high morbidity: Proposed diagnostic criteria. World Journal of Dermatologyy. 2016; 5(2): 109, doi: 10.5314/ wjd.v5.i2.109.

19. Cao YS, You QX, Wang $L$, et al. [Facial Demodex infection among college students in Tangshan]. Zhongguo Ji Sheng Chong Xue Yu Ji Sheng Chong Bing Za Zhi. 2009; 27(3): 271-273, indexed in Pubmed: 19852374.

20. Raszeja-Kotelba B, Jenerowicz D, Izdebska JN, et al. [Some aspects of the skin infestation by Demodex folliculorum]. Wiad Parazytol. 2004; 50(1): 41-54, indexed in Pubmed: 16892604.

21. Forton F, Germaux MA, Brasseur T, et al. Demodicosis and rosacea: epidemiology and significance in daily dermatologic practice. J Am Acad Dermatol. 2005; 52(1): 74-87, doi: 10.1016/j.jaad.2004.05.034, indexed in Pubmed: 15627084.

22. Horváth A, Neubrandt DM, Ghidán Á, et al. Risk factors and prevalence of Demodex mites in young adults. Acta Microbiol Immunol Hung. 2011; 58(2): 145-155, doi: 10.1556/AMicr.58.2011.2.7, indexed in Pubmed: 21715284.

23. Yamashita LS, Cariello AJ, Geha NM, et al. Demodex folliculorum on the eyelash follicle of diabetic patients. Arq Bras Oftalmol. 2011; 74(6): 422-424, indexed in Pubmed: 22331115.

24. Dokuyucu R, Kaya OA, Yula E, et al. The Presence of Demodex Folliculorum in Various Obese Groups According to BMI Levels. Arch Iran 
Med. 2016; 19(3): 210-214, doi: 0161903/AIM.0010, indexed in Pubmed: 26923894.

25. Gökçe C, Aycan-Kaya Ö, Yula E, et al. The effect of blood glucose regulation on the presence of opportunistic Demodex folliculorum mites in patients with type 2 diabetes mellitus. J Int Med Res. 2013; 41(5): 1752-1758, doi: 10.1177/0300060513494730, indexed in Pubmed: 23934047.

26. Kosik-Bogacka DI, Lanocha N, Lanocha A, et al. Role of Demodex folliculorum in the pathogenesis of blepharitis. Acta Ophthalmol. 2012; 90(7): e579, doi: 10.1111/j.1755-3768.2012.02391.x, indexed in Pubmed: 22429751.

27. Kosik-Bogacka DI, Łanocha N, tanocha A, et al. Demodex folliculorum and Demodex brevis in healthy and immunocompromised patients. Ophthalmic Epidemiol. 2013; 20(3): 159-163, doi: 10.3109/092865 86.2013.789532, indexed in Pubmed: 23713917.

28. Kurt RK, Kaya OA, Karateke A, et al. Increased density of Demodex folliculorum mites in pregnancies with gestational diabetes. Med Princ Pract. 2014; 23(4): 369-372, doi: 10.1159/000363244, indexed in Pubmed: 24941974.

29. Chen W, Plewig G. Human demodicosis: revisit and a proposed classification. Br J Dermatol. 2014; 170(6): 1219-1225, doi: 10.1111/ bjd. 12850, indexed in Pubmed: 24471456.

30. Karincaoglu Y, Esrefoglu Seyhan M, Bayram N, et al. Incidence of Demodex folliculorum in patients with end stage chronic renal failure. Ren Fail. 2005; 27(5): 495-499, indexed in Pubmed: 16152985.

31. Tian Y, Li CP. Demodex infection of the eyelids in patients with eyelid investigation. Chin J Parasitol Dis Control. 2004; 17: 236-237.

32. Türk M, Oztürk I, Sener AG, et al. Comparison of incidence of Demodex folliculorum on the eyelash follicule in normal people and blepharitis patients. Turkiye Parazitol Derg. 2007; 31(4): 296-297, indexed in Pubmed: 18224620.

33. Kemal M, Sümer Z, Toker MI, et al. The Prevalence of Demodex folliculorum in blepharitis patients and the normal population. Ophthalmic Epidemiol. 2005; 12(4): 287-290, doi: 10.1080/092865805910057, indexed in Pubmed: 16033750.

34. Bevins CL, Liu FT. Rosacea: skin innate immunity gone awry? Nat Med. 2007; 13(8): 904-906, doi: 10.1038/nm0807-904, indexed in Pubmed: 17680001.

35. Lacey N, Kavanagh K, Tseng SCG. Under the lash: Demodex mites in human diseases. Biochem (Lond). 2009; 31(4): 2-6, indexed in Pubmed: 20664811.

36. Köksal M, Kargi S, Tayşi BN, et al. A rare agent of chalazion: demodectic mites. Can J Ophthalmol. 2003; 38(7): 605-606, indexed in Pubmed: 14740805.

37. Liang L, Ding $X$, Tseng SCG. High prevalence of demodex brevis infestation in chalazia. Am J Ophthalmol. 2014; 157(2): 342-348. e1, doi: 10.1016/j.ajo.2013.09.031, indexed in Pubmed: 24332377.

38. Yam JCS, Tang BSF, Chan TM, et al. Ocular demodicidosis as a risk factor of adult recurrent chalazion. Eur J Ophthalmol. 2014; 24(2): 159-163, doi: 10.5301/ejo.5000341, indexed in Pubmed: 23873491.

39. Kim JH, Chun YS, Kim JC. Clinical and immunological responses in ocular demodecosis. J Korean Med Sci. 2011; 26(9): 1231-1237, doi: 10.3346/jkms.2011.26.9.1231, indexed in Pubmed: 21935281.

40. Koo H, Kim TH, Kim KW, et al. Ocular surface discomfort and Demodex: effect of tea tree oil eyelid scrub in Demodex blepharitis. J Korean Med Sci. 2012; 27(12): 1574-1579, doi: 10.3346/jkms.2012.27.12.1574, indexed in Pubmed: 23255861.

41. Akilov OE, Mumcuoglu KY. Immune response in demodicosis. J Eur Acad Dermatol Venereol. 2004; 18(4): 440-444, doi: 10.1111/j.14683083.2004.00964.x, indexed in Pubmed: 15196158.

42. Gao YY, Di Pascuale MA, Elizondo A, et al. Clinical treatment of ocular demodecosis by lid scrub with tea tree oil. Cornea. 2007; 26(2):
136-143, doi: 10.1097/01.ico.0000244870.62384.79, indexed in Pubmed: 17251800.

43. Kheirkhah $A$, Casas $V$, Li W, et al. Corneal manifestations of ocular demodex infestation. Am J Ophthalmol. 2007; 143(5): 743-749, doi: 10.1016/j.ajo.2007.01.054, indexed in Pubmed: 17376393

44. Inceboz T, Yaman A, Over L, et al. Diagnosis and treatment of demodectic blepharitis. Turkiye Parazitol Derg. 2009; 33(1): 32-36, indexed in Pubmed: 19367544.

45. Rufli T, Mumcuoglu Y. The hair follicle mites Demodex folliculorum and Demodex brevis: biology and medical importance. A review. Dermatologica. 1981; 162(1): 1-11, indexed in Pubmed: 6453029 .

46. Diaz-Perez JL. Demodex mites in rosacea. J Am Acad Dermatol. 1994; 30(5 Pt 1): 812-813, indexed in Pubmed: 8176032.

47. Spickett SG. A preliminary note on Demodex folliculorum Simon (1842), as a possible vector of leprosy. Lepr Rev. 1961; 32: 263-268, indexed in Pubmed: 13915750.

48. Lacey N, Delaney S, Kavanagh K, et al. Mite-related bacterial antigens stimulate inflammatory cells in rosacea. Br J Dermatol. 2007; 157(3): 474-481, doi: 10.1111/j.1365-2133.2007.08028.x, indexed in Pubmed: 17596156.

49. Szkaradkiewicz A, Chudzicka-Strugała I, Karpiński TM, et al. Bacillus oleronius and Demodex mite infestation in patients with chronic blepharitis. Clin Microbiol Infect. 2012; 18(10): 1020-1025, doi: 10.1111/j.1469-0691.2011.03704.x, indexed in Pubmed: 22114987.

50. Clifford CW, Fulk GW. Association of diabetes, lash loss, and Staphylococcus aureus with infestation of eyelids by Demodex folliculorum (Acari: Demodicidae). J Med Entomol. 1990; 27(4): 467-470, indexed in Pubmed: 2388222.

51. Lee SH, Chun YS, Kim JH, et al. The relationship between demodex and ocular discomfort. Invest Ophthalmol Vis Sci. 2010; 51(6): 2906-2911, doi: 10.1167/iovs.09-4850, indexed in Pubmed: 20130278.

52. Wolf R, Ophir J, Avigad J, et al. The hair follicle mites (Demodex spp.). Could they be vectors of pathogenic microorganisms? Acta Derm Venereol. 1988; 68(6): 535-537, indexed in Pubmed: 2467494.

53. Hallur V, Singh G, Rudramurthy SM, et al. Demodex mite infestation of unknown significance in a patient with rhinocerebral mucormycosis due to Apophysomyces elegans species complex. J Med Microbiol. 2013; 62(Pt 6): 926-928, doi: 10.1099/jmm.0.054338-0, indexed in Pubmed: 23475907.

54. Schmidt P, Kocięcki J, Dalz M, et al. Chronic Demodex related blepharitis: new aspects of treatment. Farm Wspót. 2010; 3: 210-213.

55. Chovatiya RJ, Colegio OR. Demodicosis in Renal Transplant Recipients. Am J Transplant. 2016; 16(2): 712-716, doi: 10.1111/ajt.13462, indexed in Pubmed: 26431451.

56. Filho PA, Hazarbassanov RM, Grisolia AB, et al. The efficacy of oral ivermectin for the treatment of chronic blepharitis in patients tested positive for Demodex spp. Br J Ophthalmol. 2011; 95(6): 893-895, doi: 10.1136/bjo.2010.201194, indexed in Pubmed: 21349944.

57. Brown M, Hernández-Martín A, Clement $A$, et al. Severe demodexfolliculorum-associated oculocutaneous rosacea in a girl successfully treated with ivermectin. JAMA Dermatol. 2014; 150(1): 61-63, doi: 10.1001/jamadermatol.2013.7688, indexed in Pubmed: 24284904.

58. Czepita D, Kosik-Bogacka DI. Eyelid demodicosis. Russ Ophthalmol J. 2014; 7: 107-110.

59. Nicholls SG, Oakley CL, Tan A, et al. Demodex species in human ocular disease: new clinicopathological aspects. Int Ophthalmol. 2017; 37(1): 303-312, doi: 10.1007/s10792-016-0249-9, indexed in Pubmed: 27160273. 